\title{
Class, Culture, and Pretend Play: A Reply to Sutton-Smith and Smith
}

\author{
VONNIE C. MCLOYD \\ University of Michigan
}

\begin{abstract}
It is suggested that the early studies which Sutton-Smith cites as additional support for the claim that low-income and working-class children engage in less sociodramatic and pretend play are only tangentially, if at all, related to the issue of pretend play and should, therefore, be discounted in the current dispute. High levels of physical activity are not necessarily indicative of low levels of symbolic activity. Observations in an array of settings may permit us to distinguish between children's "typical" and "best" displays of pretend behavior and determine whether there are social class differences in both symbolic competence and performance. Equally as important as further comparative, descriptive work are theoretically grounded efforts to understand pretend play, as well as other types of imaginative behavior, within the context of the instrumental competences deemed necessary for success in the child's social and cultural milieu.
\end{abstract}

In a recent paper in this journal (McLoyd, 1982), I reviewed observational studies of social class differences in children's sociodramatic and pretend play. I concluded that the popular notion that low-income and working-class children engage in less and poorer-quality sociodramatic and pretend play than middle-income children is unwarranted for two major reasons. First, the studies report discrepant and marginal findings. Second, in many of these studies, methodological procedures are flawed, social class is confounded with environmental variables which have been found to affect pretend play, and insufficient attention is given to how verbal behavior, an important medium of sociodramatic play, may be affected by situational variables. I argued further that even if consistent social class differences were found, there are no compelling explanations of the theoretical significance of such differences, since depressed levels of sociodramatic and pretend play generally have not been empirically linked to competences in low-income and working-class children. I suggested that improved assessment of social class differences should be accompanied by efforts to understand the antecedents and consequences of various expressions of imagination.

In his reply to my paper, Sutton-Smith (1983) seems to agree that many

This paper was prepared while the author was a Visiting Scholar at Stanford University and held a National Research Council Postdoctoral Fellowship for Minorities sponsored by the Ford Foundation. Requests for reprints should be sent to the author, Department of Psychology, Mason Hall, University of Michigan, Ann Arbor, MI 48109. 
of the recent studies of social class differences in sociodramatic and pretend play have fairly serious methodological flaws. Nevertheless, he maintains that these flaws do not render suspect recent findings that lowincome and working-class children engage in less sociodramatic and pretend play than middle-income children because these more recent findings parallel findings reported in several decades of prior research. I am unwilling to assume that the "history" of social class differences in play is accurate ipso facto, and even less willing to assume that it controverts the threats to validity posed by the methodological flaws in more recent research, particularly since the flaws appeared to operate systematically in favor of middle-income children (McLoyd, 1982).

Quite apart from these broader validity issues, I question whether these early findings are, indeed, in keeping with more recent reports of depressed levels of pretend play in low-income and working-class children. As evidence of the long-term consistency of social class differences in play, Sutton-Smith (1983) cites studies conducted by Lehman and Witty (1927), MacDonald, McGuire, and Havighurst (1949), Pope (1953), and Whyte (1955). It is unclear exactly which findings from these studies Sutton-Smith regards as relevant to the current dispute. He notes only that their "asserted differences are of a kind which parallels those that have appeared in the research that [McLoyd]does discuss, with lowerclass children, in general, being more physical (less symbolic) and more authoritarian (less egalitarian) in their play." One might get the impression that these studies cited by Sutton-Smith, like all of those I reviewed (McLoyd, 1982), included observational data on children's pretend play. They do not. Of four studies cited, two focus solely on children's reports of their play activities (Lehman \& Witty, 1927; MacDonald et al., 1949), onc examincd the opinions of 12-year-olds about their classmates, from which socioeconomic differences in prestige values were deduced (Pope, 1953), and one was a participant-observation study which focused, in part, on the social activities of young Italian-American men (typically between 20 and 35 years old) from working- and middle-class backgrounds (Whyte, 1955). Moreover, an examination of these studies reveals that the social class effects which they do report are related to the issue of pretend play in only the vaguest sense.

MacDonald et al. (1949) found that the reported frequency with which children read books, took music lessons, completed homework, and listened to the radio was higher, and movie attendance and outdoor evening play lower, among fifth- to seventh-grade middle-income children than low-income children. In a study of 12-year-olds, Pope (1953) reported that physical skill and prowess (e.g., fighting, engaging in active play such as baseball and football) were less important, and academic scholarship more important as determinants of peer status and reputation among middle- 
income boys than low-income boys. Skill in physical activities, such as bowling and baseball, was also found by Whyte (1955) to be a more critical determinant of social status among working-class adult males than middle-class adult males (p. 23). It is important to note, however, that both groups of males sponsored their own "community dramatics club" (pp. 49, 60-61), and acting skill appeared to be no more important in determining social status among middle-income males than among working-class males.

In the Lehman and Witty (1927) research, over 20,000 individuals between the ages of $81 / 2$ and 22 checked from a list of 200 items those "play activities" they engaged in during the prior wcek, while over 1600 children between the ages of $51 / 2$ and 8 listed their five favorite home and school activities. No social class differences among the latter children were reported. Among older respondents, the only social class difference Lehman and Witty (1927) reported was an increased tendency of highstatus individuals to report that they read books ( $p$. 184). Considerable attention was devoted to differences between white and Afro-American individuals. Though these two groups did not differ in the reported frequency of most activities (e.g., reading books and newspapers, playing house), they differed in others. Lehman and Witty attributed many of the differences which were in favor of white individuals (e.g., riding in an automobile, assembling electrical apparatus, playing basketball) to unequal income and opportunity.

This study is a particularly striking example of the tendency of researchers to look askance willy-nilly at virtually any behavior which is more frequent among low-income or nonwhite children than white, middle-income children. Lehman and Witty found that reports of engaging in social activities, playing pretend school, and writing poetry were consistently more frequent among Afro-American children ( $81 / 2$ to $151 / 2$ ) than white children. These researchers went on to point out that high levels of social participation coexist with inferior scholarship, that playing school indicated a need by the Afro-American children to compensate for the knowledge, power, and prestige they were unable to achieve in the real world, and that poetry is a more primitive mode of expression than prose (pp. 132-162).

Given that these early studies do not report social class differences in pretend play, we are left to discern the bases on which Sutton-Smith contends that they support recent findings that low-income and workingclass children are less likely than middle-income children to engage in pretend play. My best guess is that Sutton-Smith assumes that reading (a symbolic activity) and a value for scholastic achievement, shown by these studies to be associated with middle-class status (Lehman \& Witty, 1927: MacDonald et al., 1949; Pope, 1953), are positively related to a prior 
tendency to engage in pretend play. Whether this is indeed the case remains an empirical question. Sutton-Smith also seems to assume that the tendency to engage in or value physical activity, shown by these studies to be associated with low-income and working-class status (MacDonald et al., 1949; Pope, 1953; Whyte, 1955), indicates a prior or concomitant tendency to engage in low levels of symbolic activity. There are much data which run counter to the notion that high levels of physical activity are necessarily indicative of low levels of pretend play. For example, it is well known that the play of preschool boys generally involves much greater physical mobility than the play of preschool girls (e.g., Pulaski, 1970; Rubin, Maioni, \& Hornung, 1976; Sanders \& Harper, 1976), yet, preschool boys are often reported to engage in more interactive pretend play than preschool girls (e.g., Johnson \& Ershler, 1981; Rubin et al., 1976; Sanders \& Harper, 1976). In my own research (McLoyd, 1980, in press), I have frequently observed low-income Afro-American preschool boys pretend to play basketball and football and assume the imaginary identities of popular sports figures. High levels of physical activity often coexist with, rather than preclude, pretend activity in children.

Sutton-Smith (1983) correctly points out that Eifermann (1971), who found that low-income first- and second-graders engaged in more sociodramatic play than middle-income children, used criteria for the identification of sociodramatic play which were far less stringent than those used by Smilansky (1968). If Sutton-Smith thinks it judicious to discount Eifermann's contribution to the present dispute because of dubious criteria, I think it equally appropriate to discount the contribution of these early studies, as the social class effects they report are, at best, only tangentially related to pretend play. In any case, however, it is unfortunate that Sutton-Smith does not clarify the presumed links between these early studies and recent studies of social class differences in pretend play, lest the reader regard these early studies as directly relevant to the present dispute. Our goal to synthesize related and disparate research findings must be balanced against the value of meticulous, explicit, and detailed reporting as antidotes to the snowballing of misconceptions in the psychological literature.

I concur with Smith (1983) that our focus on social class should give way to efforts to locate the particular factors which underlie observed differences in pretend play. Smith seems to agree that different play forms may be functionally equivalent, but he also argues that whether differences in play forms should be viewed as differences or deficits depends on the causes of the observed differences. I believe that even before we attempt to localize the causes, we need to build a more adequate descriptive data base. Fein and Stork's (1981) suggestion that we distinguish, on an empirical basis, between children's "typical" and "best" display of 
pretend behavior bears repeating. Observations of low- and middleincome children in an array of settings would provide us with valuable information about where pretend play is most likely to occur for each group and permit intra- and intergroup comparisons. Marked intragroup discrepancies between typical and best performances would implicate environmental or motivational factors as important determinants of pretend play. It might also be argued that intergroup differences in the typical, but not the best, display of pretend play would indicate group differences in symbolic performance, not competence. Differences in competence versus performance would appear to derive from very different sources (e.g., stable background factors versus ephemeral factors). Perhaps we might avoid further confusion, and even controversy, if we clarify whether we are referring to differences in pretend play performance or competence. Smith (1983) points out that if researchers followed my suggestion (McLoyd, 1982) and familiarized low-income children with a variety of play materials, on the assumption that they were less familiar than middle-income children with such materials, and later found no social class difference in pretend play, such a finding would not discount social class differences in the "real world," if low-income children tend to have fewer play materials in most settings they encounter. In my view, such a finding would, indeed, suggest the absence of social class differences in pretend play competence, even though we might expect performance differences in the absence of this familiarization process. After all, it is highly improbable that mere elimination of environmental factors which inhibit symbolic expression also modifies the child's basic symbolic capacity.

Even as we proceed with comparative research, however, I believe that we should give increased status to the study of low-income children qua low-income children, or Afro-American children qua Afro-American children (Ogbu, 1981). This approach appears to hold much potential in our quest to understand the range of imaginative behavior in children from different socioeconomic and cultural backgrounds and the roles these different behaviors play in other developmental domains. For example, it is conceivable that certain types of pretend play (e.g., enactment of fantastic roles) are inimical to the achievement of instrumental competences which low-income parents regard as essential for their children's social and educational success. Understanding the internal logic of the social or cultural milieu within which pretend play functions is far more important theoretically, than knowing whether certain groups engage in more or less pretend play. While it is possible to study these issues conjointly, in my view, the comparative framework too often forecloses and retards serious study of more complex issues such as the relationship between certain social and cognitive behaviors and the larger cultural and social ecology. 
Some progress, albeit limited, has been made in this endeavor, an excellent example of which is the provocative ethnographic work of Sutton-Smith and Heath (1981). These researchers have given a penetrating analysis of two styles of imaginative behavior which they term oral and literary. They suggest that in cultures in which the oral style predominates, imagination is typically of a rhetorical kind which is embedded in verbal exchanges between the central performer and the group. In cultures in which the literate style predominates, imagination is often in a solitary context and emphasizes distancing from the everyday world and representation of things not present. Most intriguing is their contention that these cultural styles can be discerned in the elicited stories of children as young as 2 years of age. Those of working-class Afro-American children tended to be relatively personal in character, drawn from, but embellished beyond, real experiences, while those of white, middle-income children tended to be relatively impersonal and fantastic in character. Further descriptive work of this nature is needed if we are to fully appreciate the different styles of imaginative behavior in children from different social and cultural backgrounds. Such work may, in turn, stimulate research efforts which disclose the roles these behaviors play in other domains of social and cognitive development.

\section{REFERENCES}

Eifermann, R. R. Social play in childhood. In R. E. Herron \& B. Sutton-Smith (Eds.), Child's play. New York: Wiley, 1971.

Fein, G. G., \& Stork, L. Sociodramatic play: Social class effects in integrated classrooms. Journal of Applied Developmental Psychology, 1981, 2, 267-279.

Johnson, J. E., \& Ershler, J. Developmental trends in preschool play as a function of classroom program and child gender. Child Development, 1981, 52, 995-1004.

Lehman, H. C., \& Witty, P. A. The psychology of play activities. New York: A. S. Barnes \& Co., 1927.

MacDonald, M., McGuire, C., \& Havighurst, R. J. Leisure activities and socioeconomic status of children. American Journal of Sociology, 1949, 54, 505-519.

McLoyd, V. C. Modes of transformation in the pretend play of black, low-income children. Child Development, 1980, 51, 1133-1139.

McLoyd, V. C. Social class differences in sociodramatic play: A critical review. Developmental Review, 1982, 2, 1-30.

McLoyd, V. C. The effects of the structure of play objects on the pretend play of lowincome preschool children. Child Development, in press.

Ogbu, J. U. Origins of human competence: A cultural-ecological perspective. Child Development, 1981, 52, 413-429.

Pope, B. Socioeconomic contrasts in children's peer culture prestige values. Genetic Psychological Monographs, 1953, 48, 157-220.

Pulaski, M. Play as a function of toy structure and fantasy predisposition. Child Development, 1970, 41, 531-537.

Rubin, K. H., Maioni, T. L., \& Hornung, M. Free play behaviors in middle and lower class preschoolers: Parten and Piaget revisited. Child Development, 1976, 47, 414-419.

Sanders, K. M., \& Harper, L. V. Free-play fantasy behavior in preschool children: Rela- 
tions among gender, age, season, and location. Child Development, 1976, 47, $1182-1185$.

Smilansky, $\mathbf{S}$. The effects of sociodramatic play on disadvantaged preschool children. New York: Wiley, 1968.

Smith, P. K. Differences or deficits? The significance of pretend and sociodramatic play. Developmental Review, 1983, 3, 6-10.

Sutton-Smith, B. Commentary on social class differences in sociodramatic play in historical context: A reply to McLoyd. Developmental Review, 1983, 3, 1-5.

Sutton-Smith, B., \& Heath, S. B. Paradigms of pretense. Quarterly Newsletter of the Laboratory of Comparative Human Cognition, 1981, 3, 41-45.

Whyte, W. F. Street corner society: The social structure of an Italian slum. Chicago: Univ. of Chicago Press, 1955.

Recejved: June 15, 1982 